\title{
Dr. François Rastier* C.N.R.S. Discurso y Texto**
}

\author{
Texto traducido por el Dr. Federico Pastene Labrín***
}

La oposición entre discurso y texto ha llegado a ser común en las ciencias del lenguaje en Francia, en los "campos disciplinarios" tan diferentes como el Análisis del discurso y la semiótica de inspiración greimasiana. Sin embargo, y a partir de sus principales formulaciones, nos parece que surgen algunas problemáticas que deben ser analizadas.

Pequeña doxografía. La asimilación aparente del texto en el discurso (discourse) en Harris y los neopositivistas subyace nada menos que la ausencia del concepto filológico de texto: el discurso se reduce simplemente a una extensión de varias frases o proposiciones (cf. La teoría de Hans Kamp, la de N. Asher, etc.).

La Escuela francesa del Análisis del discurso, apoyándose primero en Harris, ha dejado atrás, sin embargo, esta concepción macrosintáctica y ha introducido una oposición explícita entre texto y discurso. No se la puede comprender sin remitirse a los objetivos ideológicos formulados por esta escuela. El principal teórico del Análisis del discurso, Pêcheux, desea estipular "los elementos estructurantes de las condiciones de producción del discurso" y concluye: "existen en los mecanismos de toda formación social reglas de proyección que establecen las relaciones entre las situaciones (objetivamente definibles) y las posiciones (representaciones de dichas situaciones)" (1990 [1969], p. 118). Estas reglas, en las cuales se reconoce la teoría leninista del reflejo, toman en cuenta además de la determinación de lo social sobre lo individual, la enunciación que manifiesta la determinación del individuo socialmente situado sobre sus producciones lingüísticas. Esto explica por qué en la intención de

* François Rastier es lingüista y semantista, director de investigación en el Centre National de la Recherche Scientifique (CNRS) de Francia. Director del Instituto de Lingüística "Ferdinand de Saussure" de París y director de la revista electrónica Texto! Textes et cultures.

Esta traducción ha sido autorizada por su autor y además agradezco la colaboración de la profesora Cecilia Aburto Durán en la revisión de este trabajo.

* RASTIER, François. Discours et texte. Texto! juin 2005 [en ligne]. Disponible en: < http:// www.revue-texto.net/Reperes/Themes/Rastier_Discours.html>.

***Chileno, Universidad del Bío-Bío, Chile. fpastene@ubiobio.cl. 
Pêcheux posición significa a la vez posición de clase y posición de habla, como si esta identificación surgiera por sí sola.

La relación entre situaciones y posiciones concierne al materialismo histórico, por esta razón, el análisis del discurso se apoya entonces explícitamente en "el análisis de la superestructura ideológica en su relación con el modo de producción que domina la formación social considerada" (Pêcheux et Fuchs, 1975, p. 15). Esto pertenecería entonces a la teoría de las ideologías, dependiente de una instancia política, y no por supuesto de una semántica, que vendría a ser la caracterización del sentido textual.

\section{ENUNCIADO + ENUNCIACIÓN (SITUACIÓN DE COMUNICACIÓN) = DISCURSO}

Con respecto a las determinaciones sociales que emplea el discurso, el texto cumple pues una función mínima. Lo testimonia la orientación de Louis Guespin: "La noción de texto, vaga e inoperante (a reserva de encontrar su validez con motivo del trabajo de D. Slakta), se sustituirá por los conceptos de enunciado y de discurso" (1971, p. 3; entre las numerosas continuaciones, cf. Viala, 1999, pp. 12-15, la sección intitulada Discours plutôt que texte). De ahí el esquema muy conocido que presenta Maingueneau (1976, p. 12):

El texto no es un tipo de enunciado. Charaudeau (1973, p. 28) ya sintetizaba así la oposición enunciado/discurso.

$\begin{array}{ll}\text { ENUNCIADO + situación de comunicación }= & \text { DISCURSO } \\ \text { uso }- \text { consenso } & \text { sentido } \\ \text { especificidad } & \text { significación }\end{array}$

Charaudeau reformula aún la separación entre las nociones de discurso y texto. Según él, el texto es "un objeto que representa la materialización de la puesta en escena de otro lenguaje. Es un resultado siempre singular de un proceso que depende de un sujeto hablante particular y de las circunstancias de producción particulares. Cada texto se encuentra pues atravesado por muchos discursos que se vinculan, cada uno, con géneros o situaciones diferentes. Por ejemplo, el género político puede estar cruzado por un discurso didáctico o por un discurso humorístico" (1988, p. 69). La confusión entre discurso y géneros es aquí patente (¿qué es el género político?).

Cualquiera que sea, la oposición discurso/texto sigue siendo hoy y a menudo reafirmada: "Nosotros admitimos, con los partidarios de la Escuela francesa del Análisis del discurso que un discurso es una producción lingüística que forma con sus condiciones de producción socio-ideológicas un todo accesible a la descripción. Admitimos además a continuación 
de los teóricos de la lingüística textual (J-M. Adam, 1990) que conviene distinguir el discurso (entendido con la acepción precedente) del texto (objeto empírico y a la vez objeto de la recepción)" (Sarfati, Remarques sur la notion de discours lexicographique, por aparecer).

Curiosamente, esta distinción es simplemente retomada, por lo demás sin mencionar su origen, por Greimas y Courtés (1979, p. 389): “Considerado en tanto como enunciado, el texto se opone al discurso, según la substancia de la expresión -gráfica o fónica- utilizada por la manifestación del proceso lingüístico. El texto sería entonces un enunciado que puede actualizarse en el discurso. Dicho de otra manera, el texto podría ser considerado como un producto, una sustancia (del lado de la lengua) y no como un proceso".

No se puede concebir cómo un texto podría preexistir a la enunciación que lo transformará en discurso, mientras se encuentra definido como expresión y producto. Pero lo esencial es que Greimas y Courtés han necesitado de la oposición discurso/texto para crear un espacio de estudio propio a la semiótica discursiva y autónoma con respecto a la semántica textual, aunque juzgada, además, como determinante para su configuración.

El contexto, es todo el texto. Si nadie ha explicado aún cómo hacer para sustraer o añadir el contexto, es sin duda un índice de que el contexto es un constituyente.

Tanto por el contenido como por la expresión, el contexto de un pasaje cualquiera es el texto entero, incluso en un corpus. Es imposible suprimir el contexto, pues al mismo tiempo se suprime la especificidad hermenéutica del objeto lingüístico, reducido entonces a una serie de caracteres. Ahora bien, una serie de caracteres es ininterpretable y no tiene ni sentido ni significación asignable. Como todo hecho semiótico complejo, un texto presenta niveles de complejidad, que se relacionan con escalas diversas. Son de tal manera que no se les puede transponer directamente las propiedades de un nivel por sobre las de otro; por ejemplo, un texto está hecho de palabras, pero una palabra no es una unidad textual.

En la oposición texto/discurso, el contexto se reduce a la situación de comunicación: es esta una herencia del positivismo lógico, como lo testimonia el levantamiento progresivo de las fronteras entre el Análisis del discurso y la pragmática. En efecto, el contexto lingüístico no está verdaderamente tomado en consideración: el texto es concebido como una dimensión del lenguaje más que como un elemento de un corpus de donde toma su sentido. Por esta razón, la palabra texto, como por 
otro lado la palabra discurso, se utiliza sólo en singular; se mantiene así en las caracterizaciones abstractas, mientras que una tipología de textos, géneros y discursos sigue siendo necesaria para el desarrollo teórico así como para las aplicaciones.

No se puede separar texto y discurso, ni teórica, ni metodológicamente. Según la tradición greimasiana, el texto es del orden de la expresión y el discurso del orden del contenido. El texto sería del dominio de la lingüística, el discurso de la semiótica. Hablar de "perspectivas diferentes" no sería aquí más que un eufemismo, pues una perspectiva no puede oponerse o conciliarse con otra sino que en el seno de una disciplina, cuando la lingüística y la semiótica permanezcan separadas.

La separación de los objetos y de las disciplinas no existe sin dificultades: por ejemplo, los autores del Diccionario de semiótica hablan de la polifonía del discurso y de las isotopías del texto, pero las isotopías sí son fenómenos semánticos. El estatus de la semántica se pone aquí problemático: es imposible en efecto diferenciar la semántica de los textos y la semiótica discursiva, si se concuerda al menos con que la lingüística es la semiótica de las lenguas; si se plantea que el discurso surge de la semiótica discursiva y el texto de la lingüística textual, se introduce una división del objeto que se transforma en un obstáculo epistemológico a la vez inútil e insuperable.

En efecto, la oposición texto/discurso conduce a una división del objeto muy difícil de sostener. Se sabe que la tradición lógico-gramatical siempre ha mantenido la separación de la expresión y del contenido, la primera asimilada al lenguaje, la segunda al pensamiento. Esta separación tradicional ha sido reforzada por el dualismo romántico.

Sin embargo, todos los autores importantes de la corriente saussuriana, y particularmente Hjelmslev, han insistido sobre el carácter indisoluble de los planos del lenguaje. Principalmente, las unidades de la expresión no son identificables ellas mismas sino por los trayectos interpretativos que ponen evidentemente en juego contenidos. Incluso las gramáticas formalistas, chomskianas principalmente, han terminado por concordar.

Si se separa, pues, el discurso y el texto para hacer del texto una manifestación superficial, se vuelve, a nuevos imprevistos, a la situación anterior a la formación de la lingüística, la de las gramáticas filosóficas surgidas de Locke (Condillac, Tracy), que han proseguido hasta la época contemporánea en la filosofía analítica del lenguaje.

En el Análisis del discurso (a la francesa), el discurso tiene lazos con la enunciación y el texto con el enunciado, aunque el texto puede definirse 
como el discurso descontextualizado, el trabajo del lingüista consiste entonces a partir desde del texto para llegar al discurso, y últimamente a sus "condiciones de producción" apoyándose principalmente sobre las pretendidas "marcas" de la enunciación, las que se creen localizables.

En relación con la oposición entre texto y discurso, el Análisis del discurso a la francesa, seguido en esto por la semiótica greimasiana, mantiene la idea tradicional de que una instancia prelingüística condiciona y determina lo lingüístico, poco importa aquí que esto prelingüístico esté hecho de condiciones sociales de producción, de un modelo constitucional semiótico, de un asunto semiótico, cognitivo o trascendental.

Al fin del trayecto generativo greimasiano, el texto llegaría a ser una variable, una manifestación "de superficie", en suma no esencial, y paradojalmente, este carácter no esencial garantizaría la transportabilidad del modelo teórico a los semióticos más diversos. Sin embargo, me parece que nada es más "profundo" que el texto: un moralista diría por otro lado que en el hombre nada es más profundo como la piel.

A veces, se puede considerar que el fin de la semiótica es conciliar texto y discurso; pero hubiera sido más simple no haberlos separado. La semiótica discursiva ha postulado esta separación para crearse un objeto disciplinario independiente de la lingüística. Se trata aquí sin embargo de política académica más que de problemática científica: de hecho, el sentido de los textos proviene ciertamente de la lingüística y no específicamente de la semiótica.

Por mi parte, he utilizado los términos de texto y de discurso en acepciones diferentes de las que ha definido el Análisis del discurso a la francesa y recuperadas por la semiótica greimasiana: los textos y los discursos (jen plural!) se encuentran (a mi parecer) exactamente al mismo nivel ontológico: por ejemplo, el discurso literario está hecho de todos los textos literarios; el texto literario no es considerado como el enunciado producido por el discurso literario, y el estudio de este discurso no ha considerado explicar los textos que le competen.

Aquí se plantea un problema de interdisciplinariedad y de estatus disciplinario: convendrá, entonces, esclarecer la relación del Análisis del discurso con la lingüística y con la historia; la relación de la semiótica (y de la "semio-lingüística") con la lingüística; de la socio-semiótica con la sociología; de la psico-semiótica con la psicología clínica, etc.

Pues la interdisciplinariedad sigue siendo incompatible con una jerarquía de las disciplinas y los objetos, aunque esté apoyada en una determinación preestablecida. Por ejemplo, lo síquico (abusivamente 
definido como prelingüístico) no determina la lingüística: se construye por dentro, opera con, etc., pero la semántica no se reduce por ello a la psicología cognitiva (como lo pretende Jackendoff, por ejemplo). Postular una determinación impediría verdaderas relaciones interdisciplinarias entre lingüística y psicología cognitiva. Lo mismo ocurriría, guardando las proporciones, para una determinación de la semiótica discursiva en la lingüística textual que se apoyaría sobre una jerarquía entre texto y discurso.

\section{Bibliografía}

Adam, J-M. 1990.

Eléments de linguistique textuelle, Bruxelles, Mardaga.

Adam, J-M. $1992 . \quad$ Les textes; types et protitypes, Paris, Nathan.

Charaudeau, P. $1983 . \quad$ Langage et discours, Paris, Hachette.

Charaudeau, P. 1992. Grammaire du sens et de l'expression, Paris, Hachette.

Greimas, A. J. \& Courtés, J. 1979.

Sémiotique. Dictionnaire raisonné de la théorie du langage, Paris, Hachette.

Guespin, L. 1971.

"Problématique des travaux sur le discours politique", Langages, 23, pp. 3-24.

Maingueneau, D. 1987. Nouvelles tendances en analyse du discours, Paris, Hachette.

Maingueneau, D. 1990. Pragmatique pour le discours littéraire, Paris, Nathan.

Maingueneau, D. 1991. L L'Analyse du discourse, Paris, Hachette.

Maingueneau, D. $1995 . \quad$ "Présentation”, Langages, 177, pp. 5-11.

Maingueneau, D. 1996. L'Analyse du discourse en France aujourd'hui, Moirand, S. (éd.), pp. 8-15.

Pêcheux, M. 1990. L'inquiétude du discourse, Paris, Éditions des Cendres (éd. D. Maldidier).

Viala, A. 1990.

"Pour une grammaire du discours: I' "ordre oratoire" face à la praelectio, une ocasión manquée", Langue française, 121, pp. 11-25. 